\title{
Does Scientific Realism Beg the Question?
}

\section{GeOFFrey Gorham}

\begin{abstract}
In a series of influential articles, the anti-realist Arthur Fine has repeatedly charged that a certain very popular argument for scientific realism, that only realism can explain the instrumental success of science, begs the question. I argue that on no plausible reading of the fallacy does the realist argument beg the question. In fact, Fine is himself guilty of what DeMorgan called the "opponent fallacy."
\end{abstract}

\section{Cornell College}

Résumé: Dans une série d'articles influents, l'anti-réaliste Arthur Fine a souvent critiqué un certain argument très courant, selon lequel seulement un réalisme scientifique peut expliquer le succès instrumental des sciences, en avançant que celuici repose sur le sophisme de la pétition de principe. Je soutiens qu'aucune interprétation plausible de ce sophisme appuie cette critique. En effet, Fine luimême commet l'erreur que DeMorgan a nommée "le sophisme de l'adversaire."

Keywords: scientific realism, begging the question, inference to the best explanation

In a series of influential articles, Arthur Fine has repeatedly alleged that a certain very popular argument for scientific realism begs the question (Fine 1984, 1986, 1991). He summarizes the realist argument as follows:

\begin{abstract}
This defense [of realism] begins by calling attention to the instrumental success of science, i.e., to the sort of practical success one can observe in our everyday lives and culture. We are then asked to account for this and are told that only realism can give a good explanation for why the conscientious practice of science leads to such instrumental success. $(1986,153)$
\end{abstract}

Fine correctly observes that the argument relies on an inference to the best explanation (IBE): "the realist contends that only the truth (or approximate truth) of science could explain its instrumental successes over time, and feels entitled to infer from this that science is true or largely so" $(1986,153)$. So the argument is:

(1) Science is (instrumentally) successful.

(2) Scientific realism is the best explanation for (1).

(3) One may infer the (probable, approximate) truth of best explanations (IBE).

(4) Therefore, scientific realism is (probably, approximately) true. 
I will call this the "standard argument" for realism since it has been at the focus of the scientific realism debate for many years. The prominent realists Boyd (1984), McMullin (1984), Thagard (1988) and Kitcher (1993, 132) all argue for realism on the basis of its supposed explanatory power. On the other side, van Fraassen $(1989,160)$ and Laudan $(1984,242)$ have claimed, respectively, that the explanatory argument for realism is incoherent and affirms the consequent. The hybrid position of entity realists like Cartwright (1983) and Hacking (1983) is grounded on a restriction of IBE to causal explanations - their special case of realism depends on a special case of this kind of the standard argument. Now if Fine is right that the standard argument merely begs the question, then this long and continuing controversy is to no purpose at all. For this reason, his charge demands close scrutiny.

According to Fine, the standard argument begs the question because it assumes the validity of IBE. He objects that since this principle has traditionally been rejected by anti-realists it cannot, in fairness, be used in support of realism:

For the issue under discussion in judging realism in this debate is precisely whether explanatory success provides grounds for belief in the truth of the explanatory story. To use explanatory success to ground belief in realism, as the explanationist defense does, is to employ the very type of argument whose cogency is the question under discussion. In this light the explanationist defense seems a paradigm case of begging the question, involving a circularity so small as to make its viciousness apparent. $(1991,82)^{\prime}$

In order to evaluate Fine's charge it is necessary to review precisely what is involved in the fallacy of petitio principii. This is a complex issue in itself. ${ }^{2}$ But I will argue that on no plausible understanding of the fallacy does the standard argument beg the question. I will consider four definitions in order of decreasing strictness.

1. According to the strictest and most common interpretation, an arguer begs the question if she "assumes as a premise for an argument the very conclusion it is intended to prove." (Copi 1986, 107) ${ }^{3}$ Often in such cases the main conclusion appears already as a premise in a sub-argument for a premise of the main argument. Such arguments are inevitably circular since the conclusion appears among its own premises. And they are obviously fallacious since the premises can provide no support that the conclusion does not possess on its own.

It seems quite clear that the standard argument for scientific realism does not beg the question in this most egregious sense. The premise to which Fine objects does not assert that realism is true, which is the conclusion of the standard argument. Rather it states that we are generally entitled to infer the truth of best explanations. These are clearly different propositions. Therefore, the argument does not assume as a premise the conclusion it aims to prove.

We can fashion an argument for realism that would beg this question in this first way: 
(1) Science is (descriptively) successful given that its theories are (probably, approximately) true.

(2) Scientific realism is the best explanation for (1).

(3) We may infer the (probable, approximate) truth of best explanations (IBE).

(4) Therefore, realism is (probably, approximately) true.

This argument definitely begs the question in the strict sense. But the problem is premise (1), not premise (3). For (1) assumes at the outset that scientific theories are (probably, approximately) true, which is just the claim of scientific realism. But no realist has proffered such an argument. Similarly, the standard argument would beg the question in the strict sense if it invoked the truth of scientific theories in support of $\mathbb{B E}$ and then wenton to invoke $\mathbb{B E}$ in supportof realism . But the standard argument does not commit this fallacy since it bases realism on IBE and not vice-versa. Nor does this appear to be Fine's complaint. He objects to "the question-begging move from explanatory efficacy to the truth of the explanatory hypothesis" (1984, 89). In other words, Fine thinks the standard argument for realism begs the question simply because it relies on IBE, not because it somehow uses realism itself to argue for realism or IBE. So no question is begged according to the strictest account of the fallacy.

2. Question-begging arguments of the first sort use their conclusions themselves as premises. A slightly weaker definition counts an argument as question-begging if it has a premise that can only be established if the conclusion is already established. Thus, Max Black says that the fallacy of begging the question occurs "when one of the premises could not be known to be true unless the conclusion were known to be true." (Black 1946, 215) ${ }^{5}$ Such arguments are inevitably circular since the conclusion must be relied on to justify the premises. ${ }^{6}$ They are fallacious because they can provide no support for the conclusion - anyone who doubted the conclusion would doubt the premises at least as much.

Does the standard argument beg the question in this second sense? I do not believe so. For the justification of IBE does not necessarily depend on the truth of scientific realism. One might argue that IBE is justified because it is reliable across a wide range of epistemic contexts that have nothing at all to do with science, much less scientific realism. For example, the judge or juror may find IBE to be a reliable guide to legal reasoning. Similarly, IBE may be a very helpful tool of the medical or automotive diagnostician. Or one might argue, with Gilbert Harman, that IBE is the best principle for distinguishing between strong and weak enumerative inductions (Harman, 1965).

The standard argument would beg the question in the second sense if the only possible justification for IBE was that it led to truth in the sciences. For in that case scientific realism, which is the conclusion of the standard argument, would already have to be established in order to establish the IBE premise. But although it is natural to suppose that IBE plays a useful part in scientific methodology, and indeed that it 
helps science get at the truth, a proponent of the standard argument does not have to believe or rely on this assumption. The standard argument's claim is simply that the explanatory power of realism gives us reason to believe realism, not that the verisimilitude of science shows explanatory power to be a mark of truth. To the extent that the IBE premise requires support of its own, there is no obvious reason to assume that it cannot be obtained independently of assumptions about science, much less scientific realism. Therefore, the standard argument does not beg the question in the second sense.

3. The first two definitions assume that circularity is an essential feature of question-begging arguments. But, according to Hamblin, "[a] question-begging argument has frequently been defined as one whose premises are at least as much in doubt as the conclusion" $(1970,247)$. This definition is much weaker than the previous two. It does not require that the premises are the same as, or even depend on, the conclusion - only that the premises are no more plausible than the conclusion. ${ }^{7}$ But even absent circularity it is easy to see why such arguments might be considered fallacious. An argument is supposed to provide reason to believe the conclusion. But if the premises are just as doubtful as the conclusion, they will be useless to support it. A possible example of question-begging in this sense would be:

(1) Animals are automata.

(2) Therefore, we have no moral obligations to animals.

Clearly, (1) and (2) are distinct and one could establish (1) independently of (2). Yet it is very unlikely that someone who was dubious about (2) would be swayed by (1). Because the premise is much less plausible than the conclusion, the argument begs the question in the third sense.

This account introduces a subjective element that was not present in the previous two. The degree to which a statement is prima facie 'doubtful' or "plausible' will depend on a person's background assumptions, personal probabilities, cultural prejudices and so on. So whether or not an argument begs the question in this third sense will depend on the relative degrees of doubt about the premises and conclusion in the mind of the person at whom the argument is directed. With respect to the issue at hand, we need to ask whether the premises of the standard argument, particularly the IBE premise, are as doubtful as the conclusion from the perspective of a typical anti-realist. If so, then the argument begs the question in the third sense.

For this purpose, let us suppose that a person's 'subjective plausibility' (SP) with respect to a given statement can normally be assigned a number between 0 and 1 . The lower the number, the greater that person's initial doubt about the statement. Now the anti-realist obviosuly comes to the standard argument with a very low SP regarding its conclusion. Call this number $\mathrm{SP}_{\text {realism. }}$. But, as Fine observes, it is a matter of historical fact that anti-realists also tend to have a very low SP for the epistemic relevance of explanatory power: 
Those suspicious of realism, from A. Osiander to H. Poincare and P. Duhem to the 'constructive empiricism' of van Fraassen, have been worried about the significance of the explanatory apparatus in scientific investigations. While they appreciate the systematization and coherence brought by scientific explanation, they question whether acceptable explanations need to be true, and hence whether the entities mentioned by explanatory principles need to exist. $(1984,85)$

In other words, the target of the standard argument probably has a very low number for $\mathrm{SP}_{\mathrm{iBE}}$. Is it so low as to render the standard argument fallacious? According to the third account, the standard argument begs the question against the anti-realist just in case the relative subjective plausibilities of a typical anti-realist are captured by:

$$
\text { (*) } \mathrm{SP}_{\mathrm{IBE}}<\mathrm{SP}_{\text {realism. }}
$$

But I think that $\left(^{*}\right)$ is probably false for most anti-realists. For notice that a person whose relative subjective plausabilities are captured by $\left(^{*}\right)$ will in general find specific instances of IBE at least as doubtful as specific claims of scientific realism. This represents a very unorthodox perspective indeed. To see this, suppose I have two scientific theories about the unobservable structure of matter. One of them $\left(T_{1}\right)$ explains a great deal of observed phenomena, much more than any of its rivals. The other $\left(T_{2}\right)$ is simply a bald speculation that explains nothing at all. An anti-realist who accepts $\left(^{*}\right)$ must hold that we have no more reason to believe $T_{1}$ than $T_{2}$. That is, such an anti-realist must hold that one is as or more rational to believe $T_{2}$ for no reason at all, than to believe $T_{\text {, }}$ on the basis of its immense explanatory power. The same odd kind of epistemic attitude would be manifest outside the scientific context. Consider an anti-realist juror who is convinced by the prosecution that the guilt of the accused would very nicely explain all the evidence that has been presented in court. If this antirealist accepts $\left({ }^{*}\right)$, then she must conclude that the prosecution has given her no more reason to believe that the accused is indeed guilty than she has to believe, say, quantum-electrodynamics. ${ }^{8}$ On the whole, even if we accept Fine's historical claim that anti-realists tend to be skeptical about IBE, it is simply implausible that very many anti-realists are as skeptical about IBE as they are about realism itself. If this is right, the standard argument does not beg the question in the third sense.

Fine clearly feels there is a very intimate relation between anti-realism and opposition to IBE. His view seems to be that the latter is somehow part and parcel of antirealism so that any bona fide anti-realist must also reject IBE. If this were true then the standard argument would beg the question in the third sense since no anti-realist could find the IBE premise any less doubtful than the realist conclusion. But it is not obvious at all why Fine believes that there is such a close relation. For it is perfectly conceivable that there are reasons to oppose realism that have nothing to do with IBE. One might ground anti-realism on strict empiricist scruples about the extent of human knowledge, for example. Such an anti-realist might be prepared to accept many ordinary applications of IBE, so long as they do not extend beyond the observable realm. And, by the same token, one can have good reasons to support IBE that do not commit one to realism, as I have suggested above. Either sort of case suggests that 
one can have reasons to find realism implausible that do not automatically render IBE equally implausible.

4. The weakest definition I can find of petitio principit holds that an arguer begs the question if she relies on an unproved or unsupported premise that is disputed by opponents of the conclusion. Oliver Johnson, for example, says that begging the question occurs "when the arguer relies on an 'ultimate principle' upon which he bases his argument and cannot or refuses to argue for that principle, yet still insists on rejecting the opposed argument" (Johnson 1967, 13). One can understand why such an argument might be deemed unsatisfactory. For inasmuch as the arguer relies on an unsupported premise that her opponent rejects, her argument gives the opponent no good reason to believe the conclusion.

This fourth interpretation is suggested by certain of Fine's statements:

For the general requirement of faimess entails that in the debate with instrumentalism the realist is not free to assume the validity of any principle that is itself under debate. I would suppose that this is a straightforward application of the rules against vicious circularity or begging the question. $(1986,83)$

But this assertion is somewhat ambiguous. On the one hand, if Fine's view is that the standard argument uses realism itself to support realism or IBE, then the charge of vicious circularity is appropriate. But we have already seen that the standard argument does not beg the question in this most egregious sense. On the other hand, if Fine's complaint is simply that the realist uses a principle that is under dispute, namely IBE, then he must understand question-begging in the very weak sense we have just introduced: the arguer relies on an unsupported or unproved premise that is disputed by the opponent of her conclusion. But viewed in this way, it is hard to see that the standard argument is really fallacious at all. If the standard argument relies on a premise whose validity has not yet been demonstrated to the satisfaction of anti-realists then in lieu of independent arguments for IBE the realist can fairly be accused of assumptionon probato, and so of propounding a weak argument. Even so, it is unfair to dismiss an argument as fallacious and circular simply because it is weak in the minds of its opponents.

Indeed, if we choose to call arguments fallacious that are weak in this sense, we will probably be forced to conclude that the bulk of philosophical arguments, including anti-realist arguments, are worthless. For example, consider a well-known objection to the standard argument originating with Laudan (1984) and endorsed by Fine $(1984,84)$. The objection is that the actual history of science severely undermines the realist assumption that the empirical success of a theory is evidence of (probable, approximate) truth. Laudan gives twelve examples of theories which are false in spite their empirical success. Now if we accept the fourth definition, the realist may answer that Laudan's argument begs the question because it assumes at the outset what a realist will dispute: that a full historical survey will find no significant correlation (or a negative correlation) between empirical success and truth. 
But as Paul Meehl has observed, the evaluation of such an assumption must wait on a proper actuarial survey of the properties and fates of scientific theories based on a random sampling of episodes from the history of science (Meehl 1992, 272). Even so, it would be unfair simply to dismiss Laudan's argument as fallacious. Better to undertake the needed evaluation of the disputed historical premise. Likewise, if the standard argument relies on a questionable premise (IBE), then the proper charge is assumptio non probato, not petitio principii. And the fair course of action is to join battle at the site of the disputed premise.

In any case, it is not clear that the standard argument begs the question in even this weakest sense. According to the fourth account, an arguer begs the question if she relies on a questionable premise that she either cannot or will not defend. But the realist does not present IBE as an article of faith. He is prepared to defend it on grounds independent of realism, as we have seen above. Suppose I presented the following argument to a U.S. gun-rights advocate:

(1) Personal gun ownership is not protected by the Second Amendment.

(2) Therefore, federal laws against personal gun ownership are not unconstitutional.

My argument would beg the question in the fourth sense if I were unwilling or unable to defend (1). But if I am prepared to defend (1), on the basis of Supreme Court rulings, for example, then the argument in no way begs the question against the gun-rights activist. Similarly, it is unfair to charge the realist with questionbegging, in even this weakest sense, so long as the realist is willing to defend the IBE premise of the standard argument.

To conclude, we have found that the standard argument for scientific realism does not beg the question if we stick to the strictest and most generally accepted definitions of the fallacy. For the argument is not circular. Neither is it obvious that the standard argument begs the question according to much weaker, less common, definitions of petitio principii, which do not require circularity. At the very least, the charge of question-begging can be challenged on several points. Therefore, those critical of the standard argument for realism should probably drop the charge of question-begging and focus instead on the substance of the realist's argument, particularly the principle of IBE. Otherwise, these critics themselves commit what DeMorgan called an opponent fallacy:

There is an opponent fallacy to the petitio principii, which 1 suspect is of the more frequent occurrence: it is the habit of many to treat an advanced proposition as begging the question the moment they see that, if established, it would establish the question. Before the advancer has more than stated his thesis, and before he has time to add that he proposes to prove it, he is treated as a sophist on his opponent's perception of the relevancy (if proved) of his first step. (DeMorgan 1847, 255)

As a scientific realist, I hereby charge Fine with this opponent fallacy. 


\section{Notes}

1 The question-begging charge is found also in Fine $(1984,84-87 ; 1986,160-63)$. See also Laudan $(1984,242)$.

${ }^{2}$ The issue has been given a very thorough treatment by Walton (1991).

${ }^{3}$ Example:

(1) No family can thrive without a male father-figure.

(2) Therefore, a male father-figure is necessary for the well-being of any family.

${ }^{4}$ Peter Lipton (1991, 158-68) thinks that the standard argument for realism begs the question in this way and therefore concludes that it is useless against anti-realism. But Lipton sees things this way only because he himself uses realism to justify IBE. I think IBE can be justified on grounds independent of scientific realism.

${ }^{5}$ Similarly, Trudy Govier's account states: "A person tries to prove some conclusion C. He chooses premises $\mathrm{P}$ that are so logically close to $\mathrm{C}$ that his opponents would already have to support $\mathrm{C}$ in order to accept those premises" $(1988,90)$.

- A standard example:

(1) The Bible is the word of God.

(2) The Bible says that God exists.

(3) Therefore, God exists.

'A few authors require only that a premise is doubtful, not necessarily more doubtful than the conclusion. For example, Hurley says that the question is begged if " $[t]$ he arguer uses some form of phraseology that tends to conceal the questionably true character of a key premise" (Hurley 1994, 152). This account apparently originates with Sidgwick (see Walton 1991, 25). I will assume that Fine does not mean to accuse realists of this kind of chicanery.

${ }^{8}$ If $\left(^{*}\right)$ does in fact capture the views of typical anti-realists, then it would probably make sense to change their label to "anti-explanationists" since they oppose IBE at least as vehemently as realism itself.

\section{References}

Black, Max. (1946). Critical Thinking. New York: Prentice-Hall.

Boyd, Richard. (1984). "Current Status of Scientific Realism." In J. Leplin (ed, ) Scientific Realism. Berkeley: U of California Press.

Cartwright, N. (1983). How the Laws of Physics Lie. Oxford: Clarendon Press.

Copi, Irving M. (1986). Informal Logic (7th Edition). New York: Macmillan.

DeMorgan. (1847). Formal Logic. London: Taylor and Walton.

Fine, Arthur. (1984). "The Natural Ontological Attitude" In J. Leplin (ed.) Scientific Realism. Berkeley: U of California Press.

. (1986). "Unnatural Attitudes: Realist and Instrumentalist Attachments to Science." Mind MCV: 149-179.

_.. (1991). "Piecemeal Realism." Philosophical Studies, 61: 79-96.

Govier, Trudy. (1988). A Practical Study of Argument. Belmont, CA: Wadsworth.

Hacking, lan. (1983). Representing and Intervening. Cambridge: Cambridge University Press. Hamblin, C. L. (1970). Fallacies. London: Methuen and Co.

Hurley, Patrick. (1994). A Concise Introduction to Logic (5th Edition). Belmont: Wadsworth. 
Johnson, Oliver A. (1967). "Begging the Question." Dialogue, 6: 135-50.

Kitcher, Philip. (1993). The Advancement of Science. Cambridge: Harvard University Press. Laudan, Larry. (1984). “A Confutation of Convergent Realism." In J. Leplin (ed.) Scientific Realism. Berkeley: U of California Press.

Lipton, Peter. (1991). Inference to the Best Explanation. New York: Routledge.

McMullin, E. (1984). "The Case for Scientific Realism." In J. Leplin (ed.) Scientific Realism. Berkeley: U of California Press.

Meehl, P. E. (1992). "The Miracle Argument for Realism." Studies in the History and Philosophy of Science, 23: 267-282.

Thagard, P. 1988. Computational Philosophy of Science. Cambridge: M.I.T. Press.

Van Fraassen, Bas. (1989). Laws and Symmetry. Oxford: Oxford University Press.

Walton, Douglas (1991). Begging the Question. New York: Greenwood Press.

GEOFFREY GORHAM DEPARTMENT OF PHILOSOPHY CORNELL COLLEGE 600 FIRST STREET WEST MOUNT VERNON, IOWA 52314 GGORHAM@CORNELL-IOWA.EDU 